\title{
Leitura do Poema II, 26 de Propércio
}

Rafael Sento-Sé Falcón

Graduação - USP

Orientador: Prof. Doutor João Angelo Oliva Neto (VERVE -USP)

\section{Resumo}

Breve tentativa de compreensão de um dos mais interessantes poemas do elegíaco latino Sexto Propércio. Pauta-se a leitura no recolhimento de recursos estilísticos pelos quais o poeta amplia a abrangência semântica da obra. Contudo, não se trata de propor uma interpretação para o poema, mas de fazer um apanhado de possibilidades.

Palavras-chave: Elegia; Literatura Latina; Propércio; naufrágio.

\section{Readings on Propertius' Poem II, 26}

\begin{abstract}
Brief comprehension attempt of one of the most interesting Latin elegiac poems of Sextus Propertius. The analysis of the poem is founded on a collection of stylistic features in which the poet broadens the semantic scope of his work. However, the aim of this paper is not to propose an interpretation of the poem, but present an outline of possibilities.
\end{abstract}

Keywords: Elegy; Latin Literature; Propertius; shipwreck. 


\section{Introdução}

O amor possuía três grandes gêneros na Roma antiga: a lírica, a elegia e bucólica. A diferença mais enfatizada entre esses gêneros provavelmente é o caráter lacrimoso da poesia elegíaca, o que não significa meramente "triste". É que a elegia, embora ressalte dores e sofrimentos de amor, não fica privada de certa felicidade e mesmo de um estranho humor; pode-se dizer até que não é raro as tristes lágrimas serem causa de conforto e prazer.

Uma diferença mais concreta entre a elegia e os demais gêneros é o metro, o dístico elegíaco, que consiste de um hexâmetro e um pentâmetro dactílico (o segundo verso sendo chamado, com maior exatidão, um "hexâmetro duplamente cataléctico"). O primeiro é feito com seis pés dáctilos (sílaba longa-sílaba breve-sílaba breve), ao passo que o segundo é exatamente como o primeiro, exceto pela falta das duas breves no último pé de cada hemistíquio. Vemos então dois dáctilos, uma sílaba longa, mais dois dáctilos e uma sílaba longa.

Sexto Propércio foi um poeta romano do círculo de Mecenas, em que convivia com homens como Virgílio e Horácio. Sua poesia é musical e suave, própria para a recitação porque agradável aos ouvidos, tanto no som como no sentido. Não obstante, Propércio impressiona ainda mais por sua habilidade de usar uma palavra para expandir o sentido de outra. Por isso Ezra Pound considerou-o um mestre da logopeia, a "dança do intelecto entre as palavras". Sendo poeta elegíaco, Propércio limou a forma do dístico rumo à perfeição, como se verá adiante. 


\section{Texto latino e tradução do poema}

Vidi te in somnis fracta, mea vita, carina

Ionio lassas ducere rore manus,

et quaecumque in me fueras mentita fateri, nec iam umore gravis tollere posse comas,

5 qualem purpureis agitatam fluctibus Hellen, aurea quam molli tergore vexit ovis.

quam timui, ne forte tuum mare nomen haberet, teque tua labens navita fleret aqua!

quae tum ego Neptuno, quae tum cum Castore fratri,

10 quaeque tibi excepi, iam dea, Leucothoë!

at tu vix primas extollens gurgite palmas saepe meum nomen iam peritura vocas.

quod si forte tuos vidisset Glaucus ocellos, esses Ionii facta puella maris,

15 et tibi ob invidiam Nereides increpitarent, candida Nesaee, caerula Cymothoë. sed tibi subsidio delphinum currere vidi, qui, puto, Arioniam vexerat ante lyram. iamque ego conabar summo me mittere saxo,

20 cum mihi discussit talia visa metus. 
Eu te vi em sonhos, meu amor, num navio destruído, a mover as fracas mãos no líquido jônio, e a confessar todas as vezes que me enganaste; e sem poder levantar do fluido os pesados cabelos, tal como, agitada pelas ondas escuras, Hele, aquela que um carneiro dourado carregou sobre o dorso macio.

Como temi que o mar ganhasse, talvez, o teu nome, e que o marinheiro, singrando, derramasse o pranto sobre tuas águas! As providências que tomei a Netuno, e com o irmão Cástor, e todas que tomei a ti, ó Leucótoe, que agora és uma deusa!

Mas tu, erguendo com dificuldade as pontas dos dedos, prestes a perecer, chamas continuamente meu nome. Se talvez Glauco tivesse visto os teus olhinhos, terias sido transformada na menina do mar jônio, e as Nereidas, a branca Neseia, a cerúlea Cimótoe, censurar-te-iam por inveja.

Mas eu vi acorrer em teu auxílio um golfinho; aquele, acho, que antes carregara a lira de Aríon. E eu já estava tentando lançar-me de um alto rochedo, quando meu medo dissipou essas visões.

\section{Breve comentário geral}

O poema II, 26 de Propércio é, sob muitos aspectos, um dos mais vivos e profundos do autor. O gosto de Propércio pela imagem, e especificamente pela visual, salta aos olhos do leitor na primeira palavra: "vi" (uidi, v. 1). Assim é a parte introdutória do poema, em que se cria a atmosfera fundamental: a visão durante os sonhos, Cíntia naufragando, enfraquecida, e confessando seus crimes de amor. 
O símile do verso 5 dá um salto da visão do naufrágio para os pensamentos do poeta a respeito da visão (entendendo-se por "poeta" aquele que diz "eu" no poema, ou seja, um construto). Comparando-se Cíntia a Hele, abrem-se portas para a poesia, que vem enriquecer com significado o suposto fato corriqueiro que é sonhar com um naufrágio: a analogia com Hele é o que permite que Propércio realize o belo eufemismo "que o mar tivesse o teu nome" (tuum mare nomen haberet, v. 7), para dizer "que morresses". Hele, afinal, deu seu nome ao Helesponto, porque lá morreu afogada; Cíntia - que, não sendo figura mitológica, não daria nome a mar algum - é alçada a essa importância por um simples símile.

Quando o poeta diz, no verso 7, quam timui, transforma seus próprios sentimentos, no objeto do discurso; trata-se de transferir o interesse de Cíntia para o que Propércio sente e faz por Cíntia. Primeiro o temor, depois as providências tomadas a deuses que protegem os navegantes, tudo tem Propércio como sujeito, e não Cíntia. Esse movimento de $t u$ para ego inverte-se no verso 11, que não por acaso começa com at $t u$, ou seja, uma conjunção adversativa e o pronome que marca a troca de sujeito.

Cíntia agoniza e chama o nome de Propércio, continuamente, depois de levantar com dificuldade as pontas dos dedos. O momento não dura muito: no verso 13 , sutilmente, o poema desvia a nossa atenção para uma elucubração sobre o que aconteceria se Glauco tivesse visto os olhos da Cíntia suplicante. Cíntia teria sido transformada em "menina do mar jônio", e criticada pelas Nereidas ciumentas. Essa digressão termina no verso 17, que começa com sed tibi: sistematicamente, Propércio marca o retorno à visão propriamente dita, usando outra conjunção adversativa seguida do mesmo pronome $t u$, embora em outro caso. No penúltimo dístico, o golfinho que salva Cíntia transforma-se em objeto de especulação de Propércio, que imagina tratar-se do mesmo golfinho responsável pelo salvamento do músico mítico Aríon. O último 
dístico, começado com iamque ego, faz o poeta retornar como sujeito, que quase se lança de um rochedo.

\section{Alguns aspectos estruturais}

Aproveita tecer comentários sobre certas curiosidades do poema em questão, sem, contudo, explorar as interpretações que suscitam. O uso de termos técnicos e de possíveis alusões, que sugerem leituras múltiplas, certamente interessa ao leitor de poesia antiga.

Interessante é verificar os termos pelos quais Propércio designa o mar jônio durante o poema: ros (v. 2), umor (v. 4), mare (v. 7) aqua (v. 8), nessa ordem. Os dois primeiros possuem, entre as acepções possíveis, a de "lágrimas". A palavra mare, que é a mais exata para "mar", só é usada no verso 7. Isso sem dúvidas traz à memória a expressão "bebedor de água" (admoram fontibus ora; Prop. 3,3,5), usada para designar o poeta elegíaco, em oposição ao "bebedor de vinho", que é o lírico1. Quando, no verso 8, as palavras fleret e aqua são colocadas lado a lado, a associação do mar ao pranto torna-se uma tentação. O elegíaco bebe água das lágrimas que chora, pois seu amor lhe traz sofrimento. As ambiguidades do poema 26 , se consideradas intencionais, podem ativar uma chave de leitura que considere o mar como o próprio fundamento da elegia, isto é, o amor elegíaco propriamente dito. Assim sendo, o "naufrágio" de Cíntia passa a ser um mergulho no amor, do qual ela se impregna.

O uso de termos técnicos do gênero elegíaco também chama atenção. Os versos 4 e 6 do poema apresentam, respectivamente, o termo grauis, usado em geral para aludir

1 CONTE, Gian Biagio, "Genre Between Empiricism and Theory", p.110, e nota 8; In ConTe, G. B. Genres and Readers. Baltimore / London: John Hopkins, 1994. 
ao gênero elevado, e mollis, que se refere ao gênero médio. $O$ primeiro adjetiva, no verso 4, os cabelos de Cíntia, que estão pesados por causa da umidade; mas a proximidade com a palavra umore, designando o mar, certamente gera alguma suspeita. Ademais, se os cabelos ficaram pesados, foi por causa da água; a própria água, então, pode ser entendida como fonte da grauitas.

O segundo caso, mollis, refere-se no verso 6 ao dorso do carneiro de ouro; interessante é que o carneiro deixou Hele cair, e a sugestão é que Cíntia, como Hele, caiu também de um dorso macio. O quiasma entre as expressões umore grauis e molli tergore (vv.4 e 6) seduz o leitor a procurar um sentido nisto. Se o mar for considerado o amor elegíaco, que é o carneiro? E qual a relação entre o carneiro, que deixa Cíntia cair, e o golfinho, que a salva? Ambos vêm acompanhados do verbo veho, "carregar", primeiro no pretérito perfeito e depois no mais-que-perfeito. Considerando que o golfinho, aparentemente, é o mesmo que carregou Aríon, ele costuma salvar poetas. Mas Propércio não diz que o animal salvou Aríon, e sim a lira Ariônia. Isso poderia ser usado para provar que Cíntia é (também) uma personificação da lira properciana? Essas são perguntas úteis para formular uma interpretação não-literal do poema.

\section{Conclusão: ironias de Propércio}

Os dois últimos versos do poema 26 intrigam. Propércio estava prestes a lançar-se de uma rocha, para salvar Cíntia, supomos. Contudo, as visões que tivera são dissipadas pelo medo. Que medo é esse? O mesmo do verso 7, timui, em que se tratava de temer pela vida de Cíntia? É possível. O medo tornar-se-ia tão grande, que Propércio despertaria do sonho a tempo de perceber que era uma ilusão. 
Contudo, é impossível não considerar que, com mais razão, o medo de morrer fez com que o poeta despertasse. Pois, já que ele vinha temendo pela vida de Cíntia desde o verso 7, por que isso não despertara antes? Ora, porque essa espécie de medo não desperta, antes torna o sonho mais real. O medo que faz acordar é o que se sente pela própria vida, e não pela dos outros.

Porém, se aceitamos essa perspectiva, não poderemos evitar imaginar o poeta covarde, com as pernas trêmulas, entreabrindo os olhos para medir a altura do rochedo de onde se lançará para salvar sua amada. Se isso não for ridículo o bastante, pensaremos também que esse amor que convive com o medo não é o mais nobre e puro; parece mesmo um pouco mesquinho e vicioso. Frustrante, na verdade. Como o dístico elegíaco, que começa prometendo epopeias, mas perde a força no segundo verso, assim é o poema 26, cujas tocantes cenas de amor dão lugar, no último verso, a uma confissão de fraqueza. A urbanidade de Propércio inclui, pelo que se vê, a capacidade de caçoar dos próprios tópoi, dando lugar a uma interpretação erudita e divertida do decorum elegíaco.

\section{Bibliografia}

ALLEN, A. "Sincerity and the Roman Elegists". In: Classical Philology, 15. Chicago: University of Chicago Press, 1950.

MARTINS, P. Sexto Propércio - Monobiblos. Éthos, Verossimilhança e Fides no discurso elegíaco do século I a.C. São Paulo: FFLCH / USP. 1996. 
OLIVA NETO, J.A. "Os Amores de Ovídio e suas recusas”. In: Letras Clássicas, 4. p.347-51. São Paulo: Humanitas, 2000.

OVÍDIO. Amores. Milão: Bur, 1985.

PROPÉRCIO. Elegies. Cambridge, Mass.: Harvard University Press, 1990.

VEYNE, P. A Elegia Erótica Romana. São Paulo: Brasiliense, 1985.

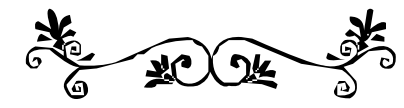

